Original Research Paper

\title{
Efficiency Estimation of Innovative Activity the Enterprises
}

\author{
Andrey Sergeevich Nechaev, Dmitry Alekseevich Antipin and Oksana Victorovna Antipina
}

Irkutsk State Technical University, Lermontov St, 83, Irkutsk, 664074, Russia Federation

\author{
Article history \\ Received: 2014-05-26 \\ Revised: 2014-06-17 \\ Accepted: 2015-01-02 \\ Corresponding Author: \\ Oksana Victorovna Antipina \\ Irkutsk State Technical \\ University, Lermontov St, 83, \\ Irkutsk, 664074, \\ Russia Federation
}

\begin{abstract}
The widely acknowledged fact is that the economic growth based only on an export of the raw materials cannot be stable for a long time and thereupon the financial support of an innovative activity gets of a special urgency. To provide higher and steady rates of an economy growth it is necessary to carry out a transition to an innovative way of the development and to spur the creation of the hi-tech manufactures. At the same time it does not mean the automatic termination of the raw materials extraction. The stocks of some kinds of them make the state the leading one in the world. The aim of the article is to review the main aspects of the selection of indicators to measure innovation in enterprises. To improve the efficiency of innovation investment enterprises must evaluate the potential of the company and on this basis to identify priority areas of investments completed. The paramount value for the given problem decision has a choice of the indicators for the estimation of the enterprises innovative activity. The paper substantiates the need for regression analysis when selecting indicators. A mathematical model using different combinations of options indicators of innovation activities of enterprises. Mathematical models are made and used for three generalized purposes such as for an explanation, a prediction and a management. The study suggested indicators for assessing the potential of the enterprise. It is necessary to prioritize the financing of innovation enterprises. In the article conclusions about possible directions for further research and also presents some limitations of the analysis.
\end{abstract}

Keywords: Finance Companies, Correlation and Regression Analysis, Performance Evaluation of Innovation

\section{Introduction}

Nowadays a modernization and a transition to innovative development of all public life spheres are the key priorities for Russia development. The considerable financial resources are required for the realization of these country priority goals and it causes the interest to the problems connected with the search and the choice of the most suitable sources for the innovative process financial maintenance.

The generally recognized fact is that the economic growth based only on the raw materials export cannot be stable for a long time and thereupon the financing of the enterprises innovative activity gets a special urgency. It is necessary to carry out the transition to an innovative way of a development to provide higher and steady rates of the economy growth and to energize the hi-tech manufactures creation. At the same time it does not mean the automatic stoppage of the extraction of the raw materials which stocks are the leading size ones of the separate kinds not only in our country but in the world. The country future development should cater for the accelerated rates of the innovative technologies adoption for the account of the raw materials disposal means and the following increase of the stuff processing level including.

Various aspects of the development of innovation in the works analyzed by (Shumpeter, 1961; Yakovets, 1999; Kondratiev, 1984; Porter, 1985; Kuznets, 1955; Drucker, 2012; 2013).

The financing of innovation activities of enterprises and analyze the potential of the enterprise is considered in works by (Folomev and Revazov, 2001; Nechaev and Prokopeva, 2013; Uvarova, 2011; Gluschenko, 2009; Sharpe et al., 1998; Janeway, 2012; Atkinson and Ezell, 2012).

But in the existing works are poorly studied the directions of investment for stimulation of the enterprises innovative activity.

\section{Methods}

As a rule an innovative activity is characterized by such problem as a high degree of an uncertainty and a risk and therefore the important principles of an 
innovative activity financial regulation are the plurality of its financing sources, the flexibility and the adaptability to quickly varying innovative processes environment what will promote the fast and effective innovations introduction for the commercial use and the return providing growth of the investments. It assumes the formation of innovative activity financial maintenance system on the basis of an optimum combination of budgetary and off-budget components. Thus it is necessary to note the importance of internal sources mobilization of the innovative sphere financing in the country.

To increase the use efficiency of the financial support received by the innovatively active enterprises it is rational to estimate the potential of the enterprise and on this basis to allocate the priority directions of the received means investment. The paramount value for the given problem decision has a choice of the indicators for the estimation of the enterprises innovative activity. For the indicators selection making the greatest impact on the results of the enterprises activity we suggest to use the correlation and regression analysis which allows to define the development laws of the studied phenomena and to reveal the difficult mechanism of the cause and effect interrelations and the dependences between the economic indicators. Besides the correlation and regression analysis allows the researchers to reveal by means of supervision both obvious (known) and the implicit (latent) dependences and to express them in the form of the formulas what gives an opportunity to simulate the phenomena or the processes mathematically.

The practical realization of the correlation and regression analysis includes some basic steps:

- $\quad$ selection of the indicators which the dependences between are the subject of an estimation

- formation of the optimum number of the most essential variable factors which influence a dependent indicator

- a choice of the communication form what means the regress equation

- an estimation of the regress function and check of the model adequacy what means the definition of regress parameters numerical values and the calculation of the indicators characterizing the spent analysis accuracy

- a comparison of the carried out analysis results with the assumptions formulated in the beginning research and the conclusions by the results of the research

\section{Results}

The research was carried in the innovatively active enterprises of Irkutsk area. For the analysis of the innovative activity were used both the official statistics and the primary data received from the reports of the innovatively active enterprises given by Territorial body of the state statistics Federal service in Irkutsk area.
The linear equation of a plural regress for revealing the dependence between indicators of the enterprises innovative activity looks like Equation 1:

$$
p_{i}=b_{0}+\sum_{j=1}^{n} b_{j} k_{j}
$$

Where:

$p_{i} \quad=$ The productive indicator of the enterprises innovative activity values received as a result of the substitution of factorial signs corresponding values in the regress equation

$b_{0} \quad=\quad$ Free factor

$b_{j} \quad=$ Model parameters (regress factors)

$k_{j}=$ Factorial quantity indicators of the enterprises innovative activity

$j=\overline{1, n}=$ Quantity of factors

The formula (1) allows to investigate the dependences between the indicators of the enterprises innovative activity and to define those of them which render the greatest value on the end results.

For the construction of mathematical models the various variants of a indicators combination of the enterprises innovative activity were used. Some mathematical models are presented below.

The plural regress equation for the dependence research of the innovative production shipped volume in million ruble, a number of the enterprise research divisions in units, the innovations expenses of the enterprise in million ruble, the number of the joint projects for the research and investigation performance in which the organization participates in the units, looks like the following Equation 2:

$p_{1}=838,75+194,01 k_{1}+17,28 k_{2}+189,16 k_{3}$

Where:

$k_{1}=\mathrm{A}$ number of the enterprise research divisions in units

$k_{2}=$ The enterprise expenses of for the innovations in million ruble

$k_{3}=$ The number of joint projects for the research and investigation performance in which the organization participates in the units

$p_{1}=$ Volume of shipped innovative production in million ruble

For the decision of a factors selection problem and the expediency of an inclusion of this or that factor in a model we will calculate the special indicators of a correlation for the selection of the indicators. Let's construct a correlation matrix (Table 1).

Now we can see that the greatest influence on the volume of the shipped production is rendered by the expenses for the innovations and number of the enterprise research divisions. 
Table 1 . The special factors of a correlation for formula 2

\begin{tabular}{lllll}
\hline & $\mathrm{p}_{1}$ & $\mathrm{k}_{1}$ & $\mathrm{k}_{2}$ & $\mathrm{k}_{3}$ \\
\hline $\mathrm{p}_{1}$ & 1 & & & \\
$\mathrm{k}_{1}$ & 0,4 & 1 & & \\
$\mathrm{k}_{2}$ & 0,6 & 0,5 & 1 & \\
$\mathrm{k}_{3}$ & 0,3 & 0,5 & 0,3 & 1 \\
\hline
\end{tabular}

The plural regress equation for the dependence research of the innovative production shipped volume in million ruble, a number of the enterprise research divisions in units, the innovations expenses of the enterprise in million rubles, the number of the joint projects for the research and investigation performance in which the organization participates in units looks like the following Equation 3:

$$
p_{2}=28,84+0,038 k_{1}+5,12 k_{2}+0,02 k_{3}
$$

Where:

$k_{1}=$ The enterprise volume of the investments of in a fixed capital in million ruble

$k_{2}=$ Number of joint projects for the research and investigation performance in which the organization participates in units

$k_{3}=$ Volume of the shipped innovative production in million ruble

$p_{2}=$ The expenses of the enterprise for the innovations in million ruble. Let's calculate the special factors of a correlation (Table 2)

Now we can see that the enterprise expenses are mostly influenced by the volume of the shipped innovative production and the volume of the investments into a fixed capital.

The plural regress equation for the dependence research of the research division number from such factors as the number of the enterprise workers having a higher education, the number of the enterprise workers having various scientific degrees, the number of the joint projects for the researches and investigation performance in which the organization participates looks like the following Equation 4:

$p_{3}=-0,08+0,27 k_{1}+0,11 k_{2}+0,03 k_{3}$

Where:

$k_{1}=$ The number of the enterprise workers having a higher education in thousand people

$k_{2}=$ The number of the enterprise workers having various scientific degrees

$k_{3}=$ The number of the joint projects for the performance of the researching and investigating in which the organization participates in units

$p_{3}=$ The number of the enterprise research divisions in units. Let's calculate the special factors of a correlation (Table 3)

The number of the research enterprise divisions highly depends on an employee's educational level. Thus the highest influence on the quantity of the research enterprise divisions renders the factor which means the number of the enterprise workers having various scientific degrees.

On the basis of the analysis made we allocate the basic indicators of the enterprises innovative activity covering all kinds of the special potentials presented in Table 4.

Table 2. The special factors of a correlation for formula 3

\begin{tabular}{lllll}
\hline & $p_{1}$ & $k_{1}$ & $k_{2}$ & $k_{3}$ \\
\hline$p_{1}$ & 1 & & & \\
$k_{1}$ & 0,5 & 1 & & \\
$k_{2}$ & 0,3 & 0,4 & 1 & \\
$k_{3}$ & 0,7 & 0,6 & 0,3 & 1 \\
\hline
\end{tabular}

Table 3. The special factors of a correlation for formula 4

\begin{tabular}{lllll}
\hline & $p_{1}$ & $k_{1}$ & $k_{2}$ & $k_{3}$ \\
\hline$p_{1}$ & 1 & & & \\
$k_{1}$ & 0,7 & 1 & & \\
$k_{2}$ & 0,9 & 0,5 & 1 & \\
$k_{3}$ & 0,5 & 0,4 & 0,4 & 1 \\
\hline
\end{tabular}

Table 4. Indicators of the enterprises innovative activity

\begin{tabular}{ll}
\hline Enterprise potential & Quantitative and quality indicators of the enterprises innovative activity \\
\hline Personal potential & Mid-annual number of the enterprise employees \\
& Number of the employees having various scientific degrees \\
Acquisition of new technologies (technological achievements: Purchase of the equipment, & the rights for patents, etc.) \\
& Number of the submitted demands for patents \\
& Quantity of the enterprise joint projects for performance of researches and investigations \\
& Investments of the enterprise into a fixed capital in ruble \\
& Presence of complete technological (grocery, process) innovations in units \\
& Presence of complete organizational innovations in units \\
& Total amount of shipped production in ruble \\
& Total amount of shipped innovative production in ruble \\
& Internal expenses of the enterprise for researches and investigations in ruble \\
& Total amount of the enterprise expenses for innovations in ruble \\
& Total amount of the enterprises expenses for technological innovations (grocery and process) in \\
thousand ruble & Enterprise profit in ruble \\
&
\end{tabular}


The selected indicators are divided into four special kinds of the enterprise potentials. The indicators of the personnel potential characterize a composition, a structure and a quality of the enterprise personnel. The scientific potential shows a research component of the enterprise. The economic potential includes the indicators characterizing the volumes of an innovative production and the enterprise investment into a fixed capital. The financial potential shows the profit and the expenses of the enterprise connected to an innovative activity. The basic advantage of the offered indicators is the choice of the most widespread of them covering all kinds of the special potentials.

\section{Discussion}

For the Russian Federation the problems connected with the successful innovative projects realization are extremely actual taking into consideration the increasing technological degradation of the manufacture. Even the scaled investments in the old technological structure cannot bring a proportional return and lead to the growth of a costs inflation only. Thereupon a mass character of the innovative projects will allow our country to reduce an existing raw dependence, to modernize the economy and to create the competitive advantages of the Russian Federation in the international market what will finally promote the increase of the citizen's life quality level. The future development of the country should be directed to the accelerated rates of the innovative technologies introduction using the incomes from a primary raw materials selling with a stage-by-stage increasing the level of its processing.

We used information from a variety of methods for selecting assessment indicators of innovative enterprises. We analyzed the indicators used by the various techniques in the estimation of the enterprises innovative activity and the efficiency of its financing: (Gadzhiev et al., 2009; Kamenskaja, 2011; Lenchuk and Vlaskin, 2005; Raevsky, 2006). As a result, based on our research and using regression analysis we have proposed indicators for full machining capacity assessment enterprise.

Authors all indicators grouped in the potentials. For example, suggests to allocate personal potential, information potential, management potential and others (Zaikina, 2010). (Korobeynikov et al., 2000) believe that it is important analysis of the scientific potential.

We shared all the indicators on the four-building: Personal potential, scientific potential, economic potential, financial potential. As the result of the analysis made by us it was revealed that the personnel, scientific, economic and financial potentials have the greatest influence on the innovative activity. The analysis made by us is supported by the practical experience of many enterprises conducting the innovative activity. For example, the personnel component of the actions being done will have the crucial importance for any enterprise engaged in the innovations. The personnel possessing higher knowledge and qualification are more productive than the other categories of the employees and are capable to generate the effective ways of realization these or those production processes. The other potentials revealed by us possess not the smaller importance too.

\section{Conclusion}

Thus, we used the correlation and regression analysis for the purpose of the most significant indicators selection for an estimation of innovative activity financing efficiency of the enterprises. The correlation and regression analysis allows to define the laws of the studied phenomena development and to understand the difficult mechanism of cause and effect interrelations and dependences between the economic indicators more deeply. Besides, the correlation and regression analysis allows researchers to reveal by means of supervision not only obvious (known) but also the implicit (latent) dependences and to express them in the form of the formulas or mathematically to simulate the phenomena or processes. Thus mathematical models are made and used for three generalized purposes such as for an explanation, a prediction and a management. In the course of the innovative-active enterprises financing arises the necessity of achievement of the similar purposes such as the estimations of enterprise potential, the forecasting and on the basis of the received results the definition of the most effective tools for financing the enterprises innovative activity. The above-mentioned shows that the application of the correlation and regression analysis is quite reasonable.

A number of limitations of the analysis performed have to be mentioned. First, the use of regression analysis is possible when there is sufficient number of observations for the study. In practice, it is considered that the number of observations should be not less than 5.6 times the number of factors. Secondly, the initial set of values should be qualitatively homogeneous. Thirdly, the fact that correlation does not give reason to believe that one of the variables is the reason for the change, or what variables are causally linked, but not observed effect of the third factor.

Further studies can be directed to the use of indicators to assess the potential of enterprise. It is necessary to identify the problems in the innovation activities of enterprises and determining funding to address these issues. For example, if after the analysis of the potentials revealed that the company has problems in personal potential, it is necessary to program being developed to attract young professionals to work in the field of innovation. 
In addition, further studies may be associated with the development of tools (algorithms, models, methods) to identify promising areas of the enterprise.

\section{Acknowledgement}

The authors acknowledge receiving support from state-funded research program of Irkutsk State Technical University. We are responsible for all errors as well as heavy style of the manuscript.

\section{Author's Contributions}

The authors of this article are working together to study issues such as: Increasing innovation activity of enterprises; sources of funding for innovation; evaluating the effectiveness of innovation. Some of the results of joint research presented in this article.

\section{Ethics}

This research based on the use of official statistical information about the activities of innovation active enterprises.

\section{References}

Atkinson, R.D. and S.J. Ezell, 2012. Innovation Economics: The Race for Global Advantage. 1st Edn., Yale University Press, ISBN-10: 0300205651, pp: 440.

Drucker, P.F., 2012. Innovation and Entrepreneurship. 1st Edn., Routledge, ISBN-10: 1136017615, pp: 272.

Drucker, P.F., 2013. On innovation. 1st Edn., Boston: Harvard Business School Publishing Corporation, pp: 176.

Folomev, A. and V. Revazov, 2001. Innovative Investment. 1st Edn., St. Petersburg: Science, pp: 184.

Gadzhiev, U., V. Akopov and M. Styrov, 2009. Interregional distinctions in scientificallyinnovative potential of the Russian federation. Soc. Econ., 2: 156-179.

Gluschenko, I., 2009. Policy innovation financing enterprise. Finance Credit, 18: 35-45.
Janeway, W.H., 2012. Doing Capitalism in the Innovation Economy: Markets, Speculation and the State. 1st Edn., Cambridge University Press, Cambridge, ISBN-10: 1107031257, pp: 340.

Kamenskaja, O.V., 2011. Complex quality standard of innovative activity. Russ. Bus., 4: 43-48.

Kondratiev, N.D., 1984. The Long Wave Cycle. 1st Edn., E.P. Dutton, New York: Richardson and Snyder, ISBN-10: 0943940079, pp: 138.

Korobeynikov, O.P., A.A. Trifilova and I.A. Korshunov, 2000. Role of innovation in the formation of enterprise strategy. Managem. Russ. Abroad, 3: 29-43.

Kuznets, S., 1955. Economic growth and income inequality. Am. Econ. Rev., 45: 1-28.

Lenchuk, E.B. and G.A. Vlaskin, 2005. Financing of innovative activity in Russia. EKO, 12: 9-26.

Nechaev, A.S. and A.V. Prokopeva, 2013. Key features of risks of company innovative activities. Midd. East J. Sci. Res., 17:

Porter, M.E., 1985. Competitive advantage. New York: Free Press.

Raevsky, S.V., 2006. Investment activity in region. Moscow: Publishing house, pp: 158.

Sharpe, W., G. Alexander and W. Bailey, 1998. Investments. 1st Edn., Prentice Hall Investments, pp: 962.

Shumpeter, J., 1961. The Theory of Economic Development. New York: Oxford University Press.

Uvarova, S.P., 2011. Formation of innovative processes tax stimulation system in economy of Russia. Finance Cred., 35: 19-25.

Yakovets, Y., 1999. Cycles. Crises. Forecasts. Moscow: Nauka, pp: 448.

Zaikina, N.A., 2010. Method of assessing the effectiveness of innovation departments of industrial enterprises. J. Econ., 6: 63-67. 